a combined proximity-spraying index was calculated, respectively measuring the lifetime average distance of home from spraying, lifetime average frequency of spraying on farm and both.

Results The median age of the boys was 11 years (range: 7-19 years). More than $60 \%$ boys had height \& weight measurements $<50$ th percentile for age (according to CDC growth charts). The median distance of home to nearest spraying area was $100 \mathrm{~m}$ (range: 17.5-974.5 m) and median number of spraying days per annum on farm was 90 (range: 50-180). The proximity index was also associated with shorter stature $(\beta$ $=0.0032, p=0.03$ ) adjusting for household income and alcohol intake during pregnancy. Further analysis is underway exploring the relationships between exposure indices and outcomes.

Conclusions Preliminary results indicate that lifetime environmental exposure to pesticides have adverse effects on the height of boys.

\section{THE RELATIONSHIP BETWEEN PESTICIDES EXPOSURE MEASURED BY MEANS OF ENVIRONMENTAL EXPOSURE INDICES AND ANTHROPOMETRIC MEASUREMENTS OF BOYS LIVING ON FARMS IN THE RURAL WESTERN CAPE}

Achieng Ochieng, ${ }^{1}$ Mohamed Aqiel Dalvie, ${ }^{1}$ Hans Kromhout ${ }^{2}{ }^{1}$ University of Cape Town, Cape Town, South Africa; ${ }^{2}$ Utrecht University, Utrecht, The Netherlands

10.1136/oemed-2011-100382.46

Objectives Many contemporary pesticides used for spraying on agricultural crops have been shown to be hormonally active. This study investigated the effect of pesticide exposure, measured by means of environmental exposure indices, on pubertal growth of boys residing in the rural Western Cape.

Methods A cross-sectional study of 269 boys including 176 boys residing on farms and 93 not residing on farms was conducted in the rural Western Cape. Tests included a questionnaire (items on demographics, birth weight, general and reproductive health, diet, residential history, pesticide exposures and mother's exposures during pregnancy) and height, weight and BMI of boys. A proximity, spraying intensity and 